\title{
Can We Integrate Psychoanalytic Models of the Mind?: The Contemporary Psychoanalytic Model of the Mind
}

\author{
Jin Hong Park \\ Department of Psychiatry, Korean Armed Forces Capital Hospital, Seongnam, Korea
}

\section{정신분석적 마음의 모델들은 통합될 수 있을까?: 오래된 강의에서 찾아가는 현대 정신분석적 마음의 모델}

박 진 홍

국군수도병원 정신건강의학과

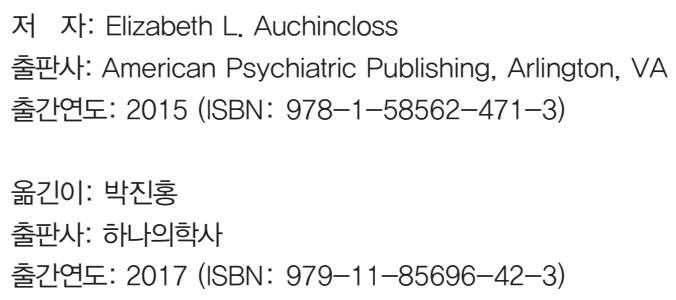

엘리자베스 오킨클로스(Elizabeth L. Auchincloss)는 다가 올 2017년 11월 한국정신분석학회의 초청으로 첫 내한하여 며칠간 세미나를 열 예정이다. 2015년에 미국에서 출판된 본 책은 2017년 한국에서 번역서로 출판되었다. 때마침 번역 작 업을 하며 여러 차례 이를 정독했던 한 명의 독자로서 책을 소개하고자 한다.

먼저 저자에 대해 소개하면 Elizabeth L. Auchincloss는 미국 정신분석의 메카인 뉴욕에서 컬럼비아 의과대학을 졸 업하여 코넬대학병원에서 전공의를 수료하고 컬럼비아 정신 분석연구소에서 분석가 과정을 졸업하고 현재까지 뉴욕에 거 주하며 활동하고 있는 정신분석가이자 '교육자'이다. 그녀는 현재 와일-코넬대학교 의과대학 정신과의 교육부과장(vice-

Address for correspondence: Jin Hong Park, MD

Department of Psychiatry, Korean Armed Forces Capital Hospital, 81 Saemaeul-ro 177beon-gil, Bundang-gu, Seongnam 13574, Korea

Tel: +82-31-702-1563, Fax: +82-31-706-0987

E-mail: jinhong.park@daum.net

This is an Open Access article distributed under the terms of the Creative Commons Attribution Non-Commercial License (http://creativecommons.org/licenses/by-nc/4.0) which permits unrestricted non-commercial use, distribution, and reproduction in any medium, provided the original work is properly cited. chair for education)이며 2014년까지 20년 이상 전공의 수련 프로그램의 책임자(director of residency training)였다. Psychoanalytic Electronic Publishing에서 검색되는 논문들을 살 펴보면 절반 가량은 정신분석의 교육과 관련된 논문이다. 그 가운데는 학부생(undergraduate student)을 대상으로 프로이 트에 대해서 강의를 했던 경험을 소개한 흥미로운 논문 (Auchincloss와 Kravis 2000)도 있다. 코넬대학교 정신과 전 공의를 대상으로 본 책과 동일 제목의 'The psychoanalytic model of the mind' 강의를 가르치고 있으며, 컬럼비아 대학 부속 정신분석연구소에서 교육 및 지도정신분석가로서 활동 하고 교육과정위원장(chair of curriculum committee)을 맡 기도 하였으며 최근에는 선임부소장(senior associate director)을 역임하고 있다. 비교적 익숙한 Arnold Cooper의 논문 집(Cooper 2005)의 편집자-논문집의 서문과 후에 그의 부고 (Tuckett 등 2012)를 쓰기도 하였던 애제자이기도 하며 대부 분의 경력도 그의 자리를 물려받았다-, Psychoanalytic terms and concepts 4판(Auchincloss와 Samberg 2012)의 공동 책 임편집자로 정신분석학계에서 알려져 있다. 본 책의 마지막 장에서 밝히듯이 Psychoanalytic terms and concepts의 편 집을 맡으면서 정신분석적 마음의 모델들을 통합시키는 관 점에 대하여 깊게 고민하였다고 한다. 경력의 대부분을 전공 의, 정신분석연구소 후보생들의 교육 활동에 쏟아왔던 배경 에서 본 책이 나올 수 있었다고 추측해본다.

저자는 독자 범위를 정신보건분야의 여러 직종, 수련생, 의과대학생에 이르기까지 추측하고 있다. 이 책은 전공의 2 년차를 대상으로 주 1 시간 총 24주 동안 가르치는 동일한 제 목의 강의에서 출발한 것이라고 하며, 책 전반에 걸쳐서 이를 
느낄 수 있다. 즉, 정신분석뿐만 아니라 미래의 다양한 정신 과학 분야에서 일하게 될 전공의들이 '정신분석적 마음의 모 델'을 이해하여 연구 및 진료에 활용할 수 있도록 내용의 주 제와 범위를 설정한 것으로 보인다.

본 책은 총 6 부(1부: 기초, 2 부: 지형학적 모델, 3 부: 구조 적 모델, 4 부: 대상관계이론과 자기심리학, 5 부: 통합과 응 용, 6 부: 부록)로 구성되어 있다. 1 부에서 마음, 정신분석적 마음의 모델의 기원, 역동적 무의식의 진화, 정신분석적 마 음의 모델에서의 핵심차원을 설명하며 차근차근하게 이야기 를 풀어나가고 있다. 역사 이야기가 때로는 지루하게 느껴질 수도 있지만 우리가 환자의 현재를 이해하기 위해 과거력, 발달력을 알아야 하듯이 정신분석적 이론을 이해하기 위해 서도 이론이 세워진 배경과 그 의미에 대해서 이해하려면 역 사는 필수적이다. 프로이트가 무의식을 발견하기 전부터 무 의식에 대해서 학자들이 알고 있었다는 점부터 데카르트, 메 스너, 브로이어에 이어 프로이트가 무의식의 존재에 대한 확 신을 갖고 이를 치료에 활용하는 과정까지 소개한다.

이 책의 백미는 1 부의 마지막 4 장에서 마음의 모델에서의 핵심차원을 규정하고 이를 통해 각 모델을 도표로 요약하고 있는 부분이다. 그 핵심 차원은 지형(topography), 동기(motivation), 구조/과정(structure/process), 발달(development), 정신병리(psychopathology), 치료법(therapeutic)이다. 각각 의 핵심 차원들의 의미를 설명하고 이후 책 전반에 걸쳐 핵 심 차원들을 통해 지형학적 모델, 구조적 모델, 대상관계이 론, 자기심리학을 조직화시켜서 설명함으로써 독자들이 각 모델들의 개념을 보다 선명하게 이해하도록 돕고 있다. 아울 러 저자는 각 장마다 초반부에 주요 정신분석 용어와 개념들 을 선정하여 나열하고 본문과 부록의 '용어해설'에서 짧지만 핵심적인 내용으로 그 의미를 기술, 요약한다. 정신분석이론 이 줄글이나 어려운 전문 용어들로 가르치는 것과 달리 주요 용어들의 의미를 명확하게 설명하고 이를 바탕으로 핵심차 원들을 설명하여 각 이론이 어떻게 구성되어 있는지 체계적 으로 설명한다는 점이 이론을 처음 접하는 학생들에게 매우 교육적이다. 아울러 각 장마다 마지막에 인용 문헌들을 정리 하여 놓았는데 정신분석의 역사에 있어서 기념비적인(monumental) 논문과 단행본들을 살펴볼 수 있다. 이를 통해 관 심있는 독자들이 더 깊이 공부할 수 있도록 배려한 점이 돋 보인다.

2 부, 3 부에서는 프로이트가 환자를 통해 알게 된 무의식이 란 개념을 통해 어떻게 지형학적 모델과 구조적 모델을 발전 시켜 나갔는지 설명한다. 기존에 쓰여진 이론서와의 차별점 은 이 과정을 설명하는 것에서 그치지 않고 현대 정신분석학 의 관점은 어떻게 변화하였는지 또한 주변 인접학문들의 어
떤 개념들이 프로이트가 소개한 개념들과 그 뜻을 같이하고 있는지 연결시키고 있다. 가령 2 부의 5 장에서 의식(consciousness)의 본성과 기능을 설명하며 인지 뇌과학의 인지적 무의 식(cognitive unconscious)을 소개하고 있다. 6장 '꿈의 세계' 에서는 꿈의 이론적 배경에 생물학적 접근을 하는 하버드 대 학의 수면 연구가 존 알랜 홉슨(John Allan Hobson)과 로버 트 맥칼리(Robert W. McCarley)의 활성화-합성 가설(activation-synthesis hypothesis)과 그 배경에 대해서 설명하고, 이에 대한 정신분석학의 입장과 최근 마크 솜즈(Mark Sol$\mathrm{ms}$ )를 비롯한 신경정신분석학자들의 연구를 소개하며 두 가지 관점을 어떻게 통합시켜 임상에서 꿈을 이해할지 설명 한다. 또한 7장 '오이디푸스 콤플렉스'에서 성 발달(gender development)과 동성애에 대한 프로이트의 의견과 다른 현 대 정신분석가들의 관점, 이론을 소개하며 정신분석학이 세 간의 편견과는 달리 끊임없이 수정되고 발달하고 있다고 강 조한다.

4부에서는 정신분석학의 다원주의(pluralism)가 현재 학 계의 흐름임을 고려하듯 대상관계이론, 자기심리학에서 주 장하는 마음의 모델들을 설명한다. 각 모델이 어떠한 배경에 서 발달하게 되었으며 자아심리학의 입장과는 무엇이 다르 며 임상적으로 어떤 환자들을 이해하는 데 도움이 되는지 설 명한다. 그 모델들의 핵심차원을 살펴보며 자연스럽게 우리 가 환자를 치료하는 데 어떻게 새로운 정신분석적 마음의 모 델들을 활용할 수 있을지 살펴본다. 이 책을 읽다 보면 자연 스럽게 마지막 장인 5 부의 13장 '통합된 정신분석적 마음의 모델을 향하여'가 어떻게 기술되어 있을지 기대하게 된다. 조 금만 언급하자면 그 역할은 온전히 임상가의 역량에 달려있 다. 물론 특정 학파의 이론을 만들고, 발달시키는 정신분석학 자들의 노력과 태도 또한 본받아야 할 모습이다. 하지만 오늘 날에 임상가로서 우리는 환자의 이야기를 들으며 어느 하나 의 모델로만 환자를 이해할 것이 아니라 다양한 모델들에 필요한 개념과 치료법을 고려하여 환자를 대할 때 보다 폭 넓고 깊게 환자를 이해할 수 있다.

본 책과 비교할 만한 책들로는 Sandler 등(1997)의 Freud's models of the mind: an introduction, Gedo와 Goldberg(1973) 의 Models of the mind: a psychoanalytic theory, Mitchell과 Black(1995)의 Freud and beyond: a history of modern psychoanalytic thought, Fonagy와 Target(2003)의 Psychoanalytic theories: perspectives from developmental psychopathology가 있다. 각자 강조하고 있는 바가 다르지만, 본 책의 차별점과 강조점은 한 학파에 머무르지 않고 정신분석학의 다원주의를 인정하고 이들의 통합을 지향한다는 점, 그리고 주변 학문(뇌과학, 인지심리학 등)과 연결점을 찾고 발전시키 
고자 노력한다는 점이다. 많은 정신분석학자들이 과거 50 70년대에 주변 학문들과 배타적으로 정신분석이론을 발 전시키고자 했던 풍토와는 달리 최근의 학자들이 Neuropsychoanalysis라는 학문 분야를 발전시키며 정신분석학을 과 학의 한 영역으로 만들고자 노력한 모습을 조금이나마 살펴 볼 수 있다.

저자와 본 책을 좋아하는 독자로서 단점을 말하기는 어려 우나 굳이 꼽자면 세 가지의 아쉬운 부분이 있다. 첫 번째로 는 비판(critique)의 부재, 두 번째로는 사례(case)의 부족, 세 번째로는 관계이론(Relational psychoanalysis) 관점의 부재 이다. 각 마음의 모델들을 설명하고 있으나 특히 자아심리 학, 대상관계이론, 자기심리학의 한계점에 대해서 자세히 설 명하고 있지 않다. 저자는 책의 목적이 통합된 관점을 찾는 것이기 때문에 이를 굳이 자세하게 기술하지 않았다고 한다. 두 번째로는 중간중간 정신분석적 마음의 모델을 설명하고 자 사례를 소개하고 있으나 그 분량이 많지 않다. 실제로는 강의나 케이스 컨퍼런스를 병행하면서 교육이 이루어졌기 때문이라고 생각한다. 세 번째로는 저자가 초반부에 밝히고 있듯이 이 책은 관계이론의 마음의 모델에 대해서는 다루지 않았다. 관계이론 자체가 갖고 있는 특성상 환자-치료자 관 계에서의 고유성 때문에 조직화시키기 어렵기 때문이라고 설명하고 있다. 그럼에도 같은 분석연구소의 Cabaniss 등 (2015)이 다른 교과서에서 관계이론에 대해서 간략하게 나 마 'Dissociated not-me self-states, Now moments'와 같은 개념들을 설명하며 다룬 것을 볼 때 추후 개정판에서는 관 계이론까지 다룰 가능성이 있다고 생각된다.
본 책은 아직 국내에 소개된 지 오래되지 않았지만 많은 수련생들에게는 강의에 활용되고, 기존에 수련을 받았던 전 문의들에게는 환자를 진료하며 어떤 '마음의 모델'을 마음 속에 갖고 앞에 앉은 환자의 마음을 이해할지 도움을 줄 수 있는 교과서이다. 또한 지도감독자, 교육자들도 다시금 주요 개념과 핵심차원들을 정리할 수 있는 책이다. 앞으로도 이와 같은 입문서들이 많이 출판되어 정신보건 분야의 종사자, 수 련생들의 교육에 활용되고 나아가 한국에서 번역서가 아닌 원저서로서도 출판되었으면 하는 바람이다.

\section{REFERENCES}

Auchincloss EL, Kravis NM. Teaching Freud to undergraduates: a case report. Int J Psychoanal 2000;81:753-770.

Auchincloss EL, Samberg E. Psychoanalytic terms and concepts. New Haven, CT: Yale University Press;2012.

Cabaniss DL, Cherry S, Graver RL, Schwartz AR, Moga DE. The psychodynamic model of the mind. In: Tasman A, Kay J, Lieberman JA, First MB, Riba MB. Psychiatry. 4th ed. Chichester: John Wiley \& Sons, Ltd;2015. p.463-476.

Cooper AM. The quiet revolution in American psychoanalysis: selected papers of Arnold M. Cooper. New York, NY: Brunner-Routledge; 2005 .

Fonagy P, Target M. Psychoanalytic theories: perspectives from developmental psychopathology. Philadelphia, PA: Whurr;2003.

Gedo JE, Goldberg A. Models of the mind: a psychoanalytic theory. Chicago, IL: University of Chicago Press; 1973.

Mitchell SA and Black MJ. Freud and beyond: a history of modern psychoanalytic thought. New York, NY: Basic Books; 1995.

Sandler J, Holder A, Dare C, Dreher AU. Freud's models of the mind: an introduction. Madison, CT: International Universities Press; 1997.

Tuckett D, Auchincloss EL, Fonagy P. Arnold M. Cooper MD. (19232011). Int J Psychoanal 2012;93:1085-1097. 